
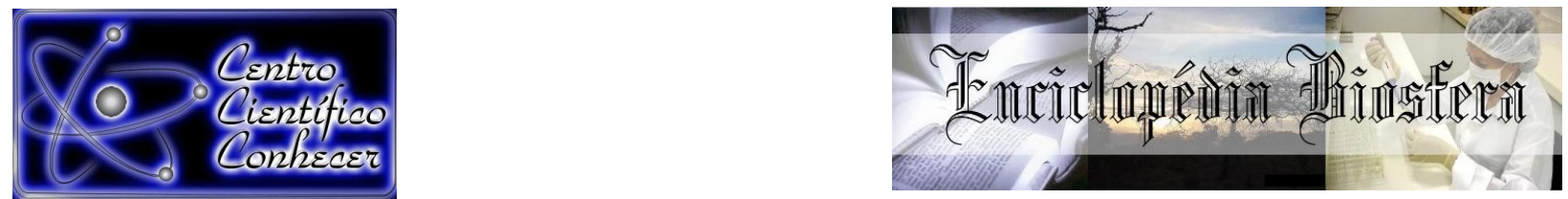

\title{
O USO DA EXPERIMENTAÇÃO COMO PROPOSTA PARA O ENSINO DE REAÇÕES QUÍMICAS
}

\author{
Wilson Flores Cabral Rotsen*1, Maria Dulcimar de Brito Silva², Victor Wagner Bechir \\ Diniz ${ }^{3}$
}

1, Graduado em Ciências Naturais com Habilitação em Química - Universidade do Estado do Pará/UEPA, Pará, Brasil-wrotsen@hotmail.com

2. Mestre em Química de Produtos Naturais -Universidade do Estado do Pará/UEPA

3. Doutor em Química Analítica - Universidade do Estado do Pará/UEPA, Pará, Brasil

Recebido em: 06/04/2018 - Aprovado em: 10/06/2018 - Publicado em: 20/06/2018 DOI: 10.18677/EnciBio_2018A111

\begin{abstract}
RESUMO
As reações químicas têm se mostrado um assunto com significativo grau de abstração, isto ocasiona dificuldades para o aluno assimilar o conteúdo e associá-lo com seu cotidiano. Por isto, buscou-se viabilizar uma metodologia de ensino baseada em experimentos de reações químicas, a fim de proporcionar melhor compreensão dos alunos pelo assunto citado em uma turma da Primeira Série do Ensino Médio, da rede pública de Belém-PA. Foi realizada uma prática, a qual foi dividida em três momentos: aula em sala sobre reações químicas; aula experimental, a qual continha cinco experimentos bastante visuais e entrevista com os alunos. Foi observado que todos os entrevistados responderam de forma satisfatória à associação dos conteúdos de sala de aula com a experimentação. $80 \%$ dos alunos entrevistados conseguiram compreender melhor o experimento que mais Ihe chamou atenção, sendo este um experimento bastante visual, comprovando que a experimentação é válida para o ensino de reações químicas, pois a prática experimental e a contextualização do conteúdo, além de tornarem as aulas mais dinâmicas e interativas, faz com que os alunos tenham maior interesse pelo assunto.
\end{abstract}

PALAVRAS-CHAVE: Ensino de química, experimentação, reações químicas.

\section{THE USAGE OF EXPERIMENTATION AS A PROPOSAL OF TEACHING CHEMICAL REACTIONS}

\begin{abstract}
Chemical reactions have been shown to be a subject with a significant level of abstraction, this brings difficulties for the student to assimilate the topic and to connect it with their daily life. Therefore, we tried to become viable a teaching methodology based on experiments of chemical reactions, in order to provide a better understanding of the students by the mentioned subject. In a class of the First Year of a public High School, in Belém-PA, Brazil. An activity was performed, which was divided into three moments: class about chemical reactions; experimental class, which contained five highly visual experiments and interview with students. It was observed that all the interviewee answered in a satisfactory way to the association of class contents with the experimentation, $80 \%$ of the interviewed could understand
\end{abstract}


better with the experiment that attracted their attention, which this was a very visual experiment. For the reason that improves their understanding, proving that experimentation is valid for the teaching of chemical reactions, because the experimental practice and the contextualization of the content mentioned, besides it makes classes more dynamic and interactive, making students become more interested in the subject.

KEYWORDS: Experimentation, chemical reactions, teaching chemistry.

\section{INTRODUÇÃO}

A química é uma das disciplinas que os alunos apresentam maior dificuldade de aprendizado, devido ao seu alto grau de abstracionismo (SILVA, 2011). Quando se trata das dificuldades dos alunos, um dos assuntos em destaque é o estudo das reações químicas. Para Mortimer e Miranda (1995), um dos fatores que influencia é a presença de assuntos extensos, assim como, o fato de conter inúmeras generalizações.

No simulado on-line promovido pelo portal Hora Enem do Ministério da Educação, 711.746 mil alunos realizaram um teste nacional para o Exame Nacional do Ensino Médio, em maio de 2016. Entre os resultados, destaca-se "[...] com pior desempenho, geometria analítica (matemática) e reações químicas (química). $O$ menor índice de acertos foi em química, em média $29 \%$ acertaram as questões da prova [...]" (TOKARNIA, 2016).

Conforme Lima e Barbosa (2015) a partir do momento em que os alunos se deparam com assuntos abstratos, como as reações químicas, e estes não conseguem compreender o mínimo requerido para o assunto, a ciência tende a se tornar mais difícil para os mesmos, o que acaba gerando uma aversão pela ciência e/ou pela disciplina. Esta aversão também pode ser causada pelas metodologias de ensino utilizadas pelo professor, uma vez que a ciência é tratada de modo mecânico e disciplinar na qual não se procura fazer com que os alunos discutam as causas dos fenômenos ou estabeleçam relações causais, nem tampouco entendam os mecanismos dos processos que estudam.

Entre os caminhos utilizados para o processo de ensino-aprendizagem, utiliza-se a experimentação como metodologia de ensino onde o professor pode despertar o interesse do aluno para o tema a ser abordado, além de proporcioná-lo a viver novas experiências, pois segundo Júnior e Parreira (2016) a química é:

\footnotetext{
"[...] uma área do conhecimento humano, a qual lida com um mundo microscópico que apresenta dificuldades e impossibilidades de visualização, além de ser uma área na qual a maioria dos conceitos é construída a partir de modelos explicativos da realidade formados por analogias, implicando na necessidade de abstração por parte de quem a estuda."
}

Nos Parâmetros Curriculares Nacionais do Ensino Médio (1999) dentre as diversas habilidades e competências presentes, a utilização da experimentação nas aulas de reações químicas desenvolve a capacidade dos alunos de questionar processos naturais e tecnológicos, possibilitando a apresentação de interpretações e prevenção de evoluções. Uma vez que serão incentivados a reconhecer problemas relacionados à Química, adquirindo a habilidade para interpretar e criticar resultados a partir de experimentos e/ou demonstrações, e assim, reconhecer aspectos químicos relevantes no seu cotidiano. 
Nas práticas experimentais o professor tem o papel de interver junto ao aluno, de modo a despertar a curiosidade e consequentemente auxiliar no aprendizado do aluno, pois a medida que o aluno recebe estimulação, este torna-se sujeito ativo no processo de ensino-aprendizado, sendo capaz de desenvolver suas próprias tentativas. (JÚNIOR; PARREIRA, 2016).

De acordo com Silva et al. (2015) $89,19 \%$ dos alunos de uma turma, no município de Luziânia-GO, atingiram notas acima da média, devido participarem de aulas experimentais após aulas teóricas. Em uma pesquisa realizada no município de São Miguel do Guamá-PA, constatou-se que a experimentação esclarece dúvidas oriundas de aulas teóricas, uma vez que $100 \%$ dos alunos afirmaram que com a aula experimental foi possível compreender melhor o assunto abordado. (BICHO et al., 2016)

Entretanto, faz-se necessário que as atividades experimentais sejam realizadas com participação ativa do aluno, para um aprendizado mais significativo. Além disso, as instalações da escola, os materiais e os experimentos a serem feitos devem ser levadas em consideração, para que não haja danos ao patrimônio escolar e a saúde dos alunos (TAHA et al., 2016)

Diante do exposto, buscou-se proporcionar aos alunos da $1^{\circ}$ série do Ensino Médio, em uma escola da rede estadual do município de Belém, uma metodologia de ensino baseada em experimentos de reações químicas, a fim de buscar uma melhor compreensão dos alunos pelo assunto citado.

\section{MATERIAL E MÉTODOS}

Em uma turma com 22 alunos da Primeira Série do Ensino Médio de uma escola da rede pública de Belém-PA, realizou-se uma aula utilizando experimentos para o ensino de reações químicas. A aplicação foi dividida em três momentos: aulas em sala de aula; aula experimental e entrevista.

Para o primeiro momento foi demonstrado algumas das aplicações das reações químicas no cotidiano dos alunos. A partir de então, introduziu-se conceitos de fenômenos físicos e químicos, explicando suas diferenças, como reconhecer uma transformação química, sendo realizado em seguida, um exercício sobre o tema para ajudar a fixar a explicação. Utilizando imagens, questionou-se aos alunos se a imagem apresentada era um fenômeno químico ou físico e o porquê da resposta. Posteriormente, abordou-se as reações químicas inorgânicas e tipos de reações, valendo-se da linguagem cientifica, de modo apropriado para o nível de conhecimento da classe. Na aula seguinte, foi introduzido o conceito de nox, oxirredução e as leis ponderais.

O segundo momento consistiu na aula prática, na qual dividiu-se a turma em cinco grupos, em três bancadas, cada grupo continha um roteiro de experimentos, informando o nome, os materiais necessários e o procedimento. Os grupos realizaram os experimentos propostos, apresentados na tabela 1, apenas 0 experimento 03 foi realizado pelo professor. Os grupos ficaram responsáveis por anotar o que acontecia no experimento, dizer se houve ou não uma reação química e apontar como perceberam isto. Tais anotações foram utilizadas para que cada grupo elaborasse um relatório da atividade experimental e este foi utilizado como parte da $4^{a}$ avaliação da turma.

QUADRO 1 -Experimentos utilizados na prática experimental

$$
\text { Experimento } 1 \text { Reação de queima da fita de magnésio }
$$




\section{Experimento 2 Reação entre água oxigenada e batata}

\begin{tabular}{|ll}
\hline Experimento 3 & Reação entre $\mathrm{KOH}$ e alumínio metálico \\
\hline Experimento 4 & $\begin{array}{l}\text { Reação entre sulfato de cobre e palha de aço / reação } \\
\text { entre nitrato de prata e cobre metálico }\end{array}$
\end{tabular}

Experimento 5 Reação entre nitrato de chumbo e iodeto de potássio

Fonte: Autores

No terceiro momento, realizou-se a entrevista contendo cinco perguntas (Tabela 2), em que os alunos precisavam responder sim ou não e justificar sua resposta. Escolheu-se aleatoriamente 10 alunos para participarem da entrevista. Para um melhor registro, utilizou-se um celular para gravação de áudio e os alunos foram enumerados de 1 a 10 . Os alunos foram orientados a falarem o número que os corresponde antes de responderem quaisquer perguntas.

QUADRO 2: Questionário de Entrevista

1. Vocês acharam a aula produtiva ou interessante? Por quê?

2. De 1 a 5 , onde 1 é muito difícil e 5 muito fácil. Qual a dificuldade do assunto?

3. Os experimentos ajudaram a entender o conteúdo de reações químicas? Em quais experimentos?

4. Qual o experimento que mais chamou a atenção de vocês?

5. Qual experimento vocês compreenderam melhor?

Fonte: Autores

\section{RESULTADOS E DISCUSSÃO}

Ao longo das atividades foi observado que durante o primeiro momento os alunos encontravam-se um pouco tímidos, mas participativos quando solicitados. Verificou-se que um grupo de sete alunos não quis participar, mesmo após algumas tentativas de trazê-los para a aula, todos permaneciam, no fundo da sala. No exercício em que os alunos precisavam dizer se na imagem acontecia um fenômeno físico ou químico, a maioria dos alunos acertavam a resposta.

Esse método ajuda o aluno a associar a teoria com o cotidiano, uma vez que o professor explica e exemplifica o assunto através da contextualização, demonstrando que tudo que é estudado em sala de aula, tem aplicação real no diaa-dia dos alunos e torna a aprendizagem mais fácil. (SILVA, 2011). Assim como a repetição dos exercícios, pois segundo Moreira (1999, apud SCHWAHN; OAIGEN, 2008), quando há maior ênfase no reforço do conteúdo, a probabilidade de aprendizagem é maior. Na prática experimental, os alunos estavam animados, estes realizaram a maior parte dos experimentos, sendo auxiliados em alguns momentos (Figura 1). 


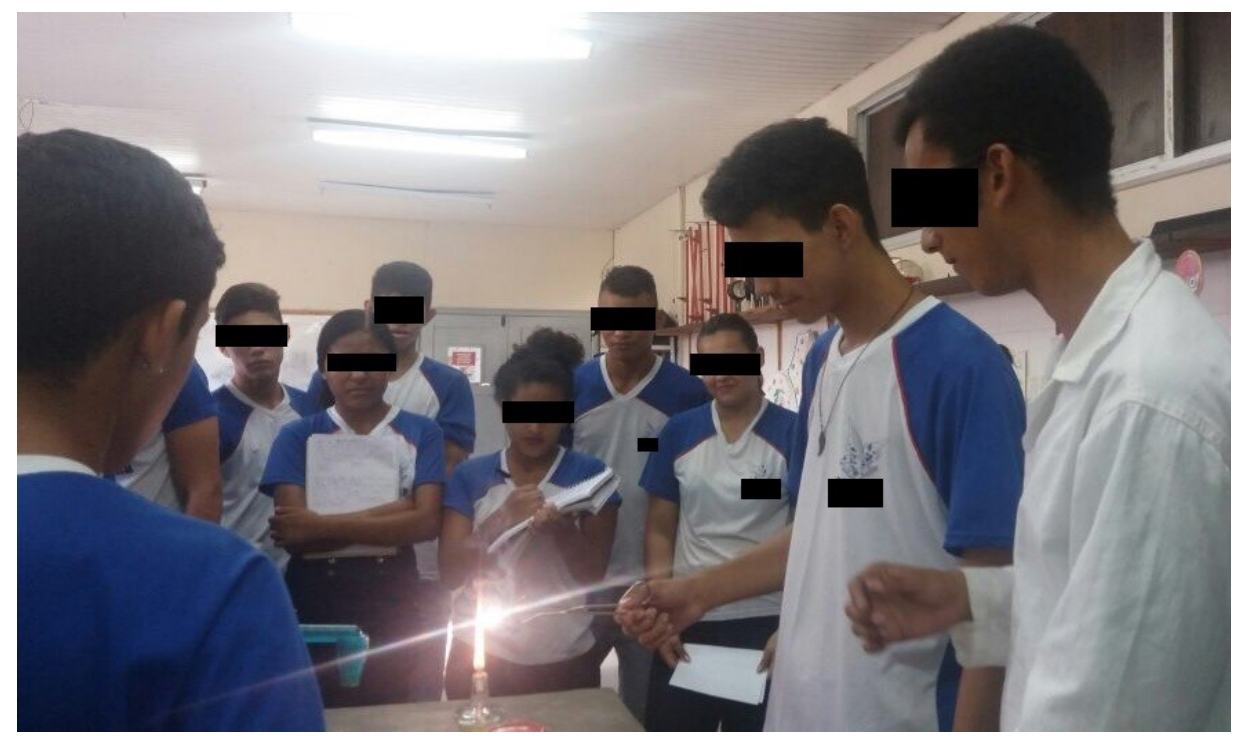

FIGURA 1: Alunos sendo auxiliados na realização do experimento 01.

Fonte: Autores

No experimento 01 ocorreu a queima da fita de magnésio, na qual $22,7 \%$ dos alunos disseram que a fita de magnésio quando colocada em contato com fogo, brilha intensamente (conforme demonstrado na Figura 1), como se fosse uma pequena lâmpada ou parecida com o flash de uma câmera de um celular, tal reação foi possível graças ao oxigênio que respiramos. Segundo $59 \%$ dos alunos (Figura 2), por ser uma reação de síntese, o magnésio reage com oxigênio e produz óxido de magnésio. 18,2\% dos alunos complementaram apresentando a equação abaixo e dizendo que "é perfeitamente visível o óxido de magnésio que resulta no final da reação (pó branco)."

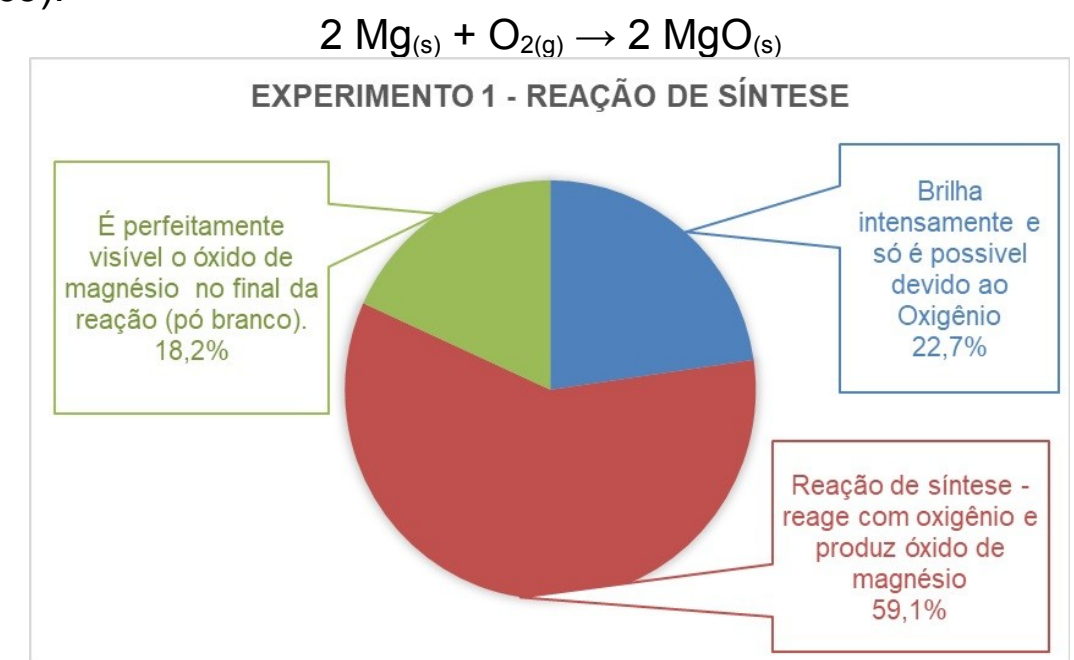

FIGURA 2: Reação de Síntese.

Fonte: Autores

As observações e conclusões dos alunos são consideradas corretas, pois de acordo com Monteiro e Vannucchi (2010) o magnésio é um metal prateado e sólido. Figueirêdo et al. (2016) provam que quando o magnésio é incinerado, emite uma luz intensa, formando o óxido de magnésio.

O experimento 2 , em que reagia um pedaço de batata com água oxigenada 10 volumes em um tubo de ensaio (Figura 3). 18,2\% (Figura 4) relataram que esta é uma reação de decomposição, onde a batata acelera a decomposição da água oxigenada. $18,2 \%$, disseram que a batata é apenas um catalisador para a reação ENCICLOPÉDIA BIOSFERA, Centro Científico Conhecer - Goiânia, v. 15 n.27; p. 8 2018 
ocorrer mais rápido, pois quando a água oxigenada é exposta a luz, ela aos poucos se dissipa. $63,6 \%$ dos alunos afirmaram a ocorrência de reação química, destes apenas $22,7 \%$ afirmaram que "forma bolhas parecidas com espumas, mas era gás oxigênio".

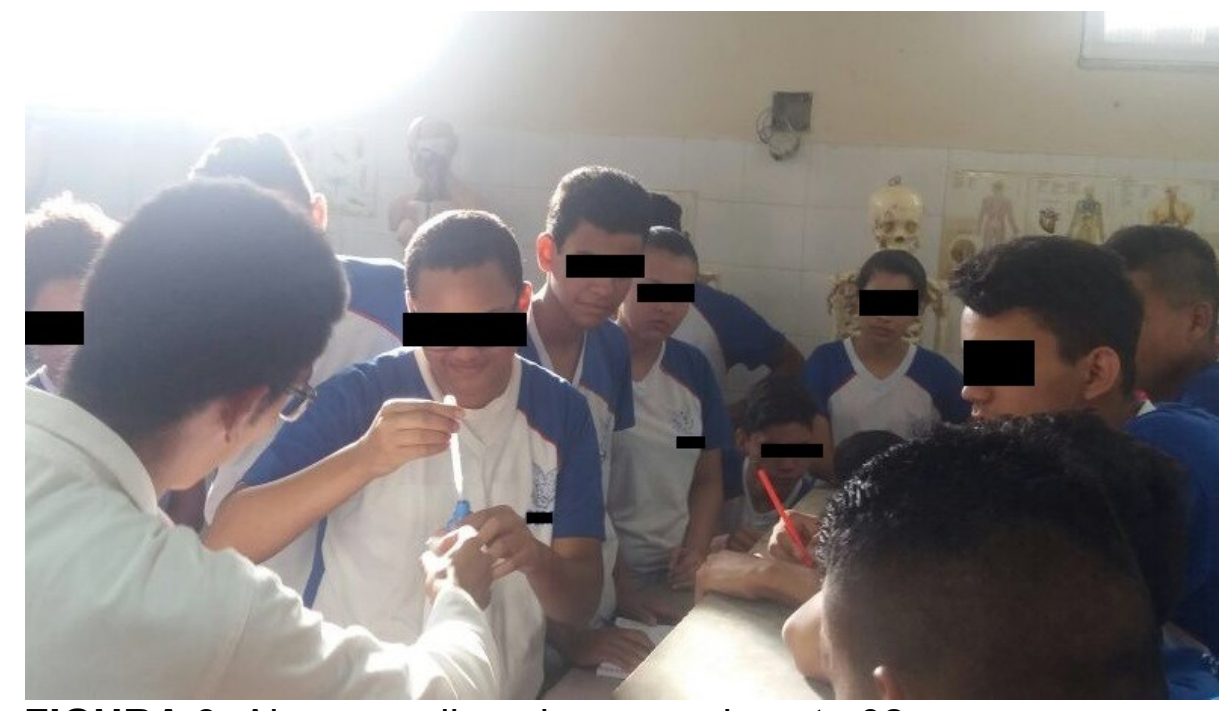

FIGURA 3: Alunos realizando o experimento 02.

Fonte: Autores

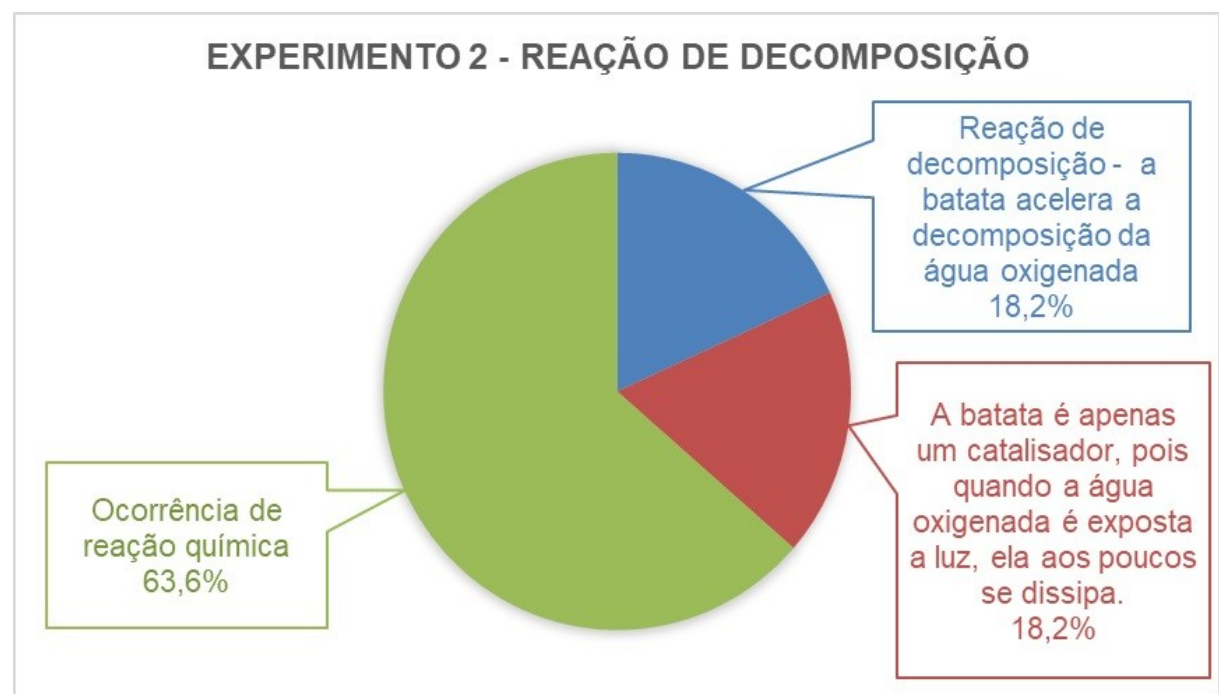

FIGURA 4: Reação de Decomposição

Fonte: Autores

A reação abaixo foi apresentada por $18,2 \%$ dos alunos (os quais haviam relatado que é uma reação de decomposição):

$$
2 \mathrm{H}_{2} \mathrm{O}_{2(\mathrm{aq})} \rightarrow 2 \mathrm{H}_{2} \mathrm{O}_{(\mathrm{l})}+\mathrm{O}_{2(\mathrm{~g})}
$$

Segundo Novaes (et al. 2013), a batata é um catalisador devido as enzimas que contém e a água oxigenada, peróxido de hidrogênio, se decompõem e libera água, oxigênio e calor. Esta reação é percebida pela liberação do gás oxigênio. Foi 
observado que, esta reação foi facilmente entendida pela maioria dos alunos, uma vez estes foram capazes de descrever o ocorrido no experimento 2.

Com o experimento 3 , em que reagiam $\mathrm{KOH}$ e alumínio, produzindo gás hidrogênio, todos evidenciaram a mudança de cor da solução, de incolor para cinza e formação de gás. 36,4\% dos alunos (Figura 5) afirmaram que ocorreu reação de simples troca e o gás produzido dentro do tubo de ensaio é o hidrogênio. Enquanto $63,6 \%$ relataram o aumento da temperatura, ou seja, uma reação exotérmica. Este experimento busca integralizar os alunos, assim como tratar sobre um tema atual e interessante (SANTOS; DA SILVA, 2015).

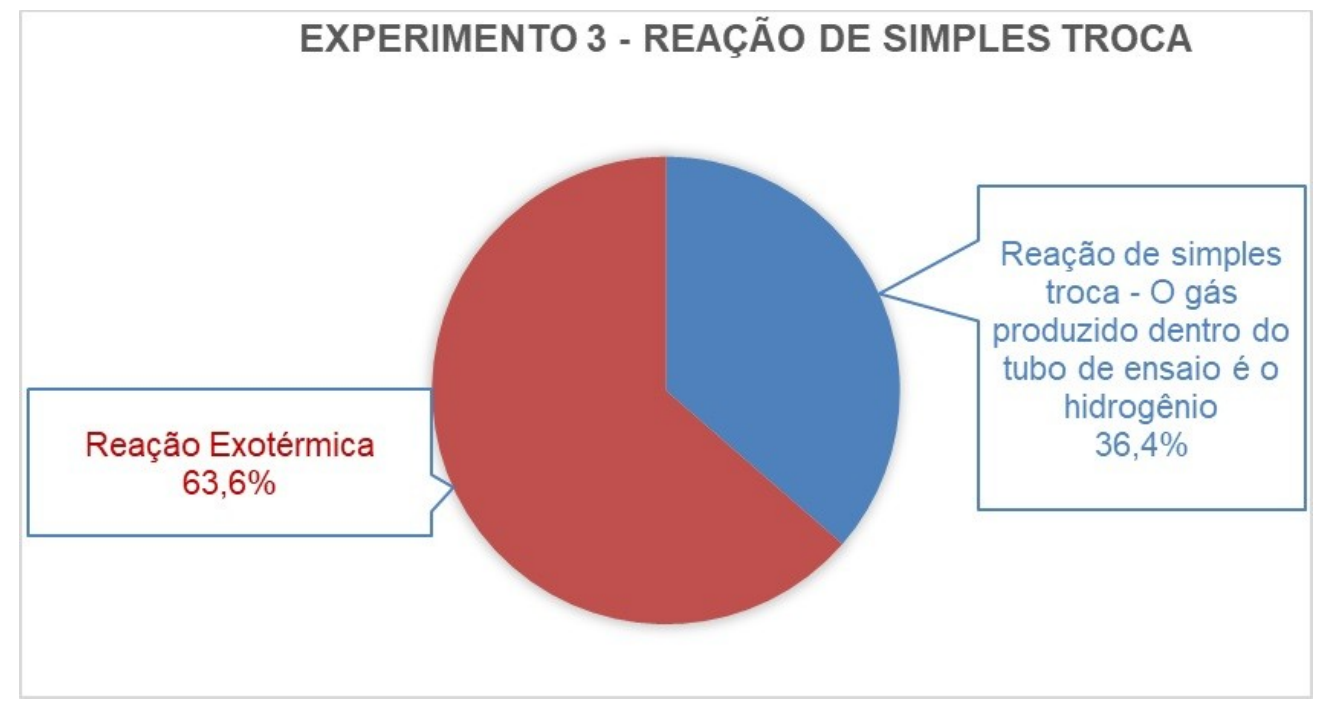

FIGURA 5: Reação de Simples Troca.

Fonte: Autores

Ao realizar o experimento 4, reação entre $\mathrm{CuSO}_{4}$ e palha de aço, 40,9\% dos alunos (Figura 6) descreveram apenas o procedimento experimental, $40,9 \%$, os quais afirmaram que na solução de cobre reagindo com a palha de aço, o ferro sofre oxidação e o cobre, redução, formando sulfato de ferro e cobre. $E$ 18,2\% não falaram do experimento. De acordo com a Fundação CECIERJ (2016), átomos de cobre que estavam em solução, depositaram-se sobre a palha de aço na forma de cobre metálico, ou seja, o cobre reduz enquanto que o ferro oxida, uma vez que os átomos de ferro metálico passaram para a solução na forma de íons $\mathrm{Fe}^{2+}$. $\mathrm{O}$ que evidencia certa dificuldade de compreender o experimento proposto. 


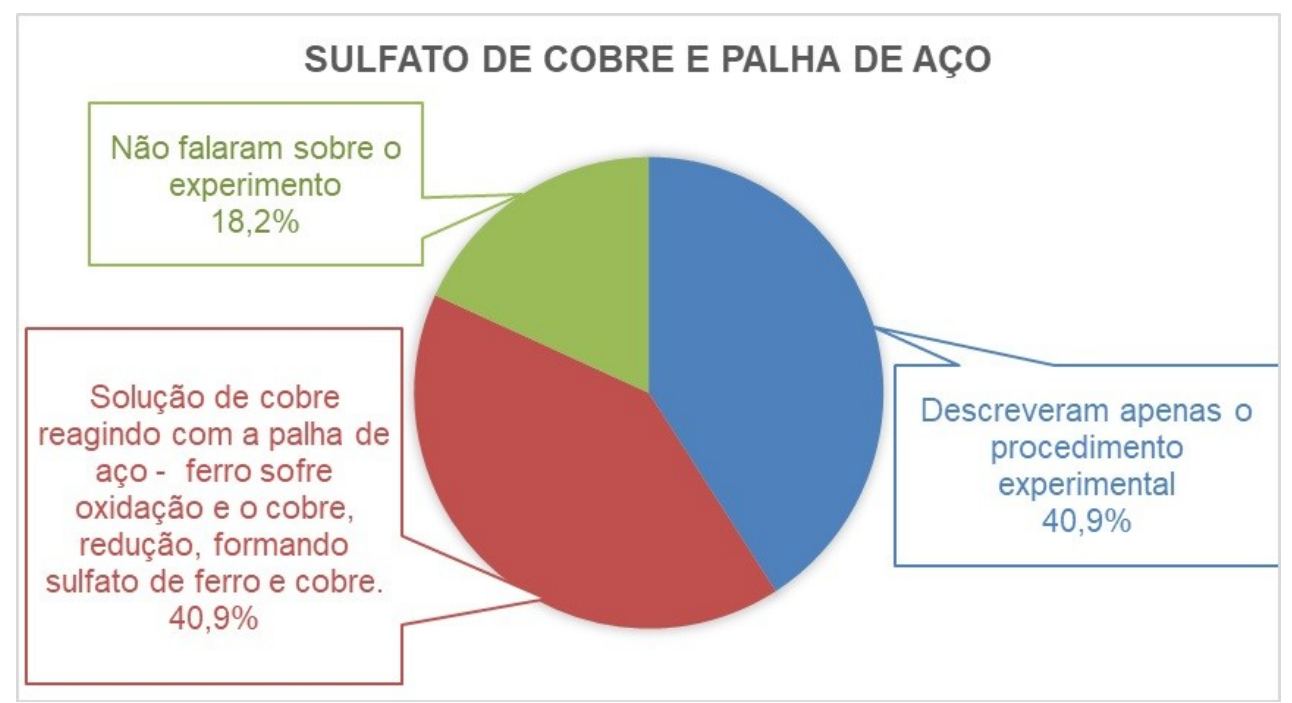

FIGURA 6: Experimento 4 - Lei de Conservação das Massas.

Fonte: Autores

Já na reação de $\mathrm{AgNO}_{3}$ e cobre, 40,9\% afirmaram que o cobre oxida e a prata reduz, produzindo nitrato de cobre e prata, ambas as reações foram caracterizadas como reações de simples troca pelos grupos. Para Barreto et al. (2017) o cobre metálico é oxidado por íons Prata, formando prata metálica que se deposita sobre o cobre. $40,9 \%$ apenas apresentaram o procedimento experimental e 18,2\% não falaram sobre o experimento.

Em relação à conservação de massa, apenas 18,2\% (Figura 7) afirmaram haver massa constante durante toda a reação, tal afirmação entra em consonância com o que aborda Martins e Martins (1993) a respeito da lei de conservação das massas, na qual segundo os autores o peso em um sistema fechado deve ser constante, uma vez que devido as reações o peso pode ser transferido entre corpos, mas não pode haver aumento ou redução de matéria. No entanto, $63,6 \%$ relataram uma pequena redução da massa ao fim da reação. $18,2 \%$ não falaram do experimento.

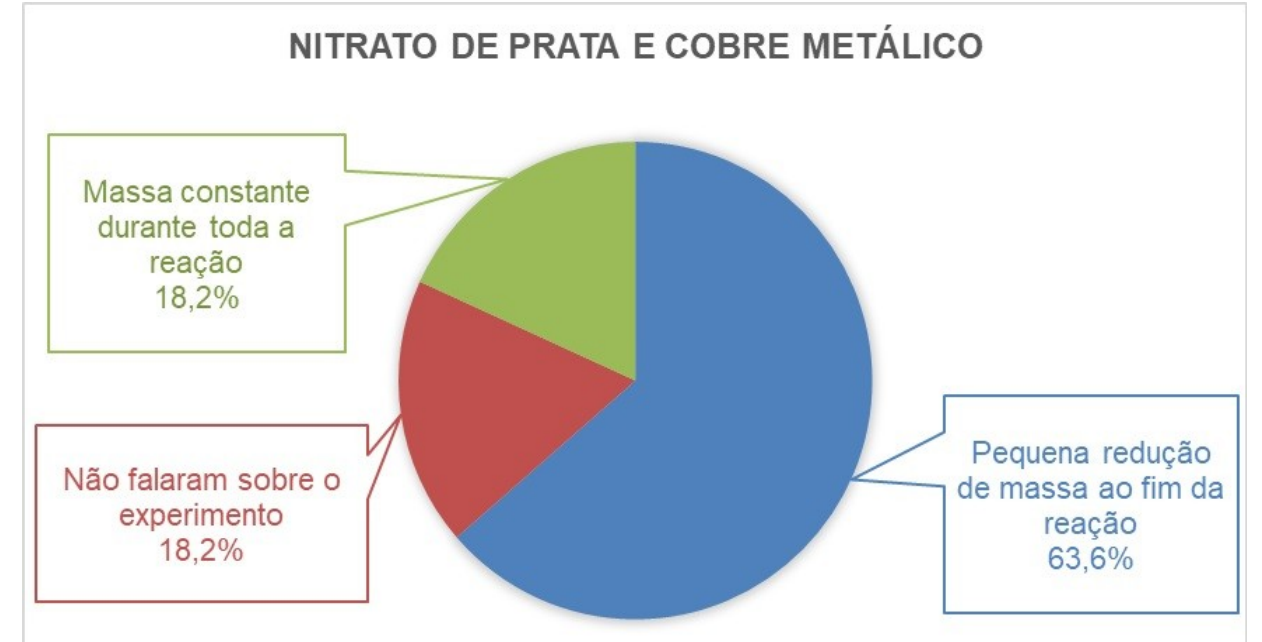

FIGURA 7: Experimento 4 - Lei de Conservação das Massas Fonte: Autores 
$\mathrm{O}$ experimento 5 , onde ocorre a mistura de $\mathrm{KI}$ e $\mathrm{Pb}\left(\mathrm{NO}_{3}\right)_{2}$, foi relatado por $18,2 \%$ dos alunos (Figura 8 ) que as soluções eram incialmente incolores, mas após a mistura, foi observado que a solução adquiriu coloração amarelo-laranja e houve a formação de um precipitado. Estes alunos caracterizaram o experimento como uma reação de dupla troca e escreveram a equação abaixo:

$$
\mathrm{Pb}\left(\mathrm{NO}_{3}\right)_{2}+2 \mathrm{KI} \rightarrow 2 \mathrm{KNO}_{3}+\mathrm{Pbl}_{2}
$$

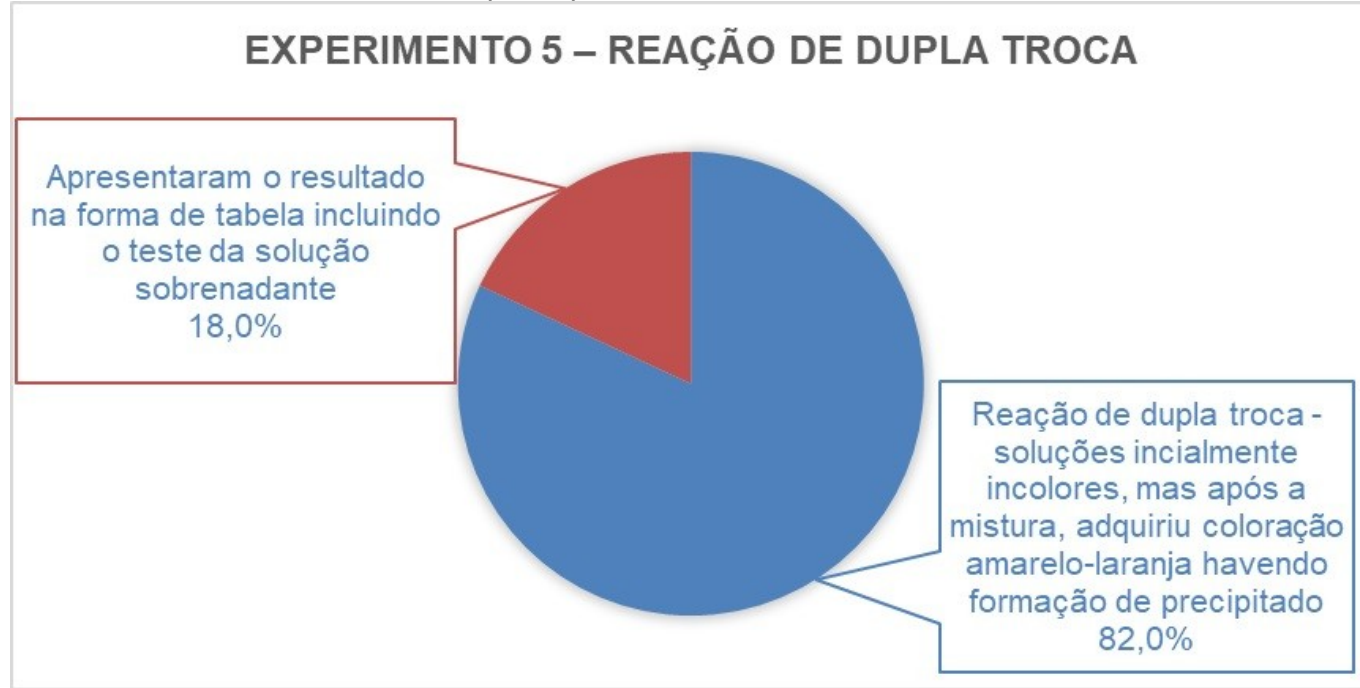

FIGURA 8: Reação de Dupla Troca

Fonte: Autores

Ainda em referência ao experimento 5 , o relato de $81,8 \%$ dos alunos se deu na forma de tabela, a qual apresentava entre outras informações, o teste da solução sobrenadante para que se pudesse confirmar se a reação foi completa e quais dos reagentes seriam $o$ reagente limitante $e$ qual $o$ reagente em excesso do experimento.

Nenhum aluno relatou, exceto pela equação química, a proporção de $\mathrm{KI}$ que reagiu com $\mathrm{Pb}\left(\mathrm{NO}_{3}\right)_{2}$ para cada tubo de ensaio, como havia sido solicitado. $\mathrm{O}$ experimento 5 (Figura 9), foi o mais complexo e mais trabalhoso para os alunos. De acordo com Atkins (2012), a formação de um determinado composto sempre acontece em proporções definidas de massas, deste modo quando não houver massa suficiente para manter a proporção, o mesmo composto não poderá ser formado.

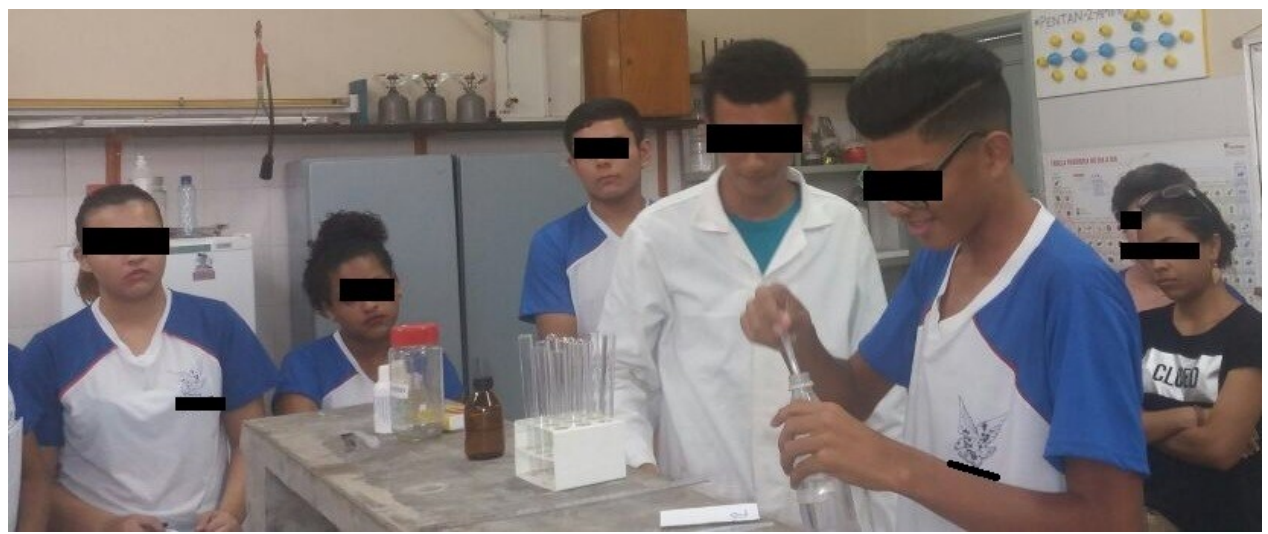

FIGURA 9: Aluno realizando o experimento 05

Fonte: Autores

Durante a entrevista quando foi perguntado aos alunos, estes disseram que a aula foi produtiva e/ou interessante, os dez alunos responderam que sim, sendo que o aluno 9 justificou dizendo, "É chato ficar só dentro de sala de aula no quadro, 
vendo tudo na prática é mais fácil de entender." De acordo com Schwahn e Oaigen (2008), a falta de atrativos em uma aula tradicional possibilita a falta de interesse do aluno, pois atualmente, o aluno não se contenta mais com conteúdo fracionados, onde não existe uma relação do que é estudado com o cotidiano. No entanto, o laboratório desperta um grande interesse no aluno, tendo caráter motivador, lúdico, vinculado aos sentidos. Podendo contribuir para uma evolução conceitual já vistos pelo aluno. Os experimentos escolhidos foram de fácil manuseio e que não apresentavam nenhum risco à saúde dos alunos. Foi pedido aos alunos para que qualificassem o assunto, quanto á sua dificuldade, sendo 1 muito difícil e 5 muito fácil, os dados foram tabulados na figura 10.

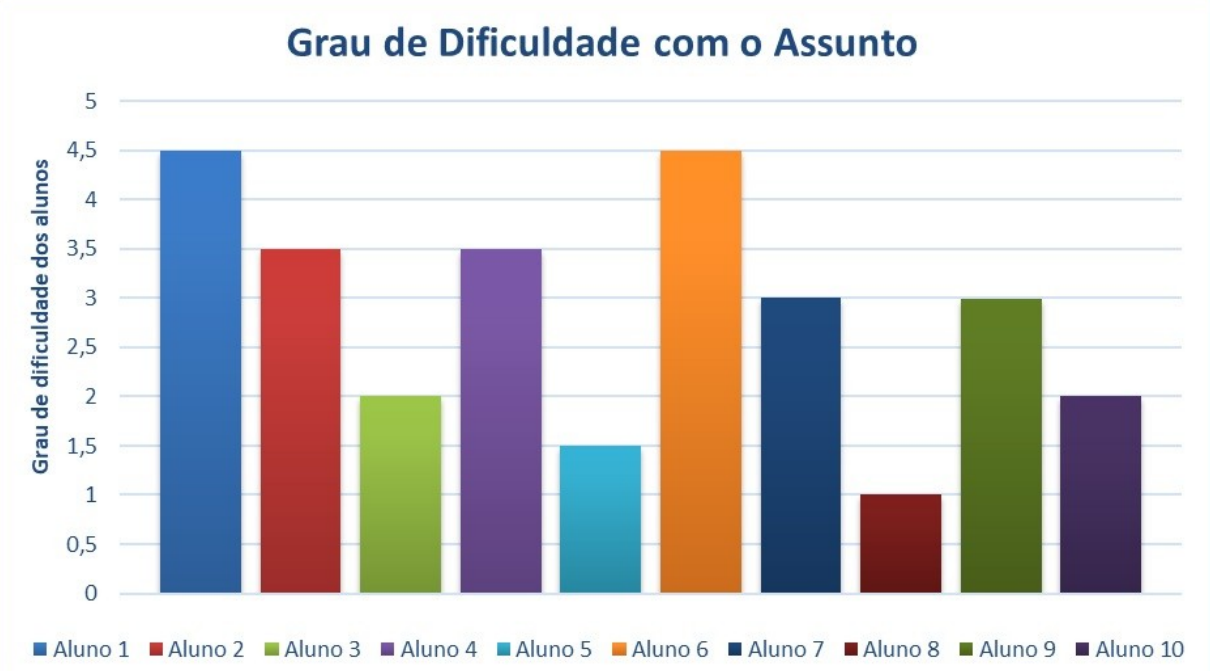

FIGURA 10: Resposta dos alunos em relação ao grau de dificuldade do assunto

Fonte: Autores

Percebe-se que $60 \%$ dos alunos consideraram o assunto de médio à fácil. $40 \%$ consideraram o assunto difícil ou muito difícil. O aluno 8 disse que "tava voando no assunto", esta afirmação fez o aluno 3 dizer "Eles não estudam", se referindo aos alunos 5 e 8 . Apesar da maioria dos alunos dizerem que gostaram da prática por terem maior envolvimento no processo de ensino-aprendizagem, a experimentação como qualquer metodologia de ensino tem limitações, não sendo possível alcançar $100 \%$ dos alunos. Segundo Martins (2014), uma turma heterogênea requer metodologias o que requer diversidade nas metodologias utilizadas, além de sistematização e organização, sendo o principal obstáculo do professor, atender estas necessidades.

Perguntou-se aos alunos se quando associamos o conteúdo de sala de aula, com o experimento se facilitaria o entendimento. Todos os alunos responderam que sim, quando perguntados como isto ajuda, o aluno 5 respondeu "fica mais fácil", o aluno 3 complementa dizendo que fica fácil porque têm-se teoria e a prática, conseguindo assim, diferenciar melhor e compreender o contexto. No momento em que o aluno participa do experimento, seu aprendizado é potencializado, proporcionando melhor compreensão do conteúdo abordado (KOGLER et al., 2014).

Ao serem questionados sobre qual experimento foi o mais chamativo (Figura 11), $60 \%$ dos alunos escolheram o experimento $3,30 \%$ o experimento 1 e $10 \%$ para o experimento 4. No entanto, quando se perguntou qual o experimento eles compreenderam melhor (Figura 12), $80 \%$ dos alunos escolheram o experimento $1 \mathrm{e}$ $20 \%$ o experimento 2. Para Taha et al. (2016), as práticas demonstrativas quando ENCICLOPÉDIA BIOSFERA, Centro Científico Conhecer - Goiânia, v. 15 n.27; p. 13 
feitas em escala macroscópica, na qual o experimento seja bonito, de modo a gerar grande impacto visual ao aluno, pois ajuda a estimular e despertar o interesse dos alunos na prática e nos conceitos abordados.

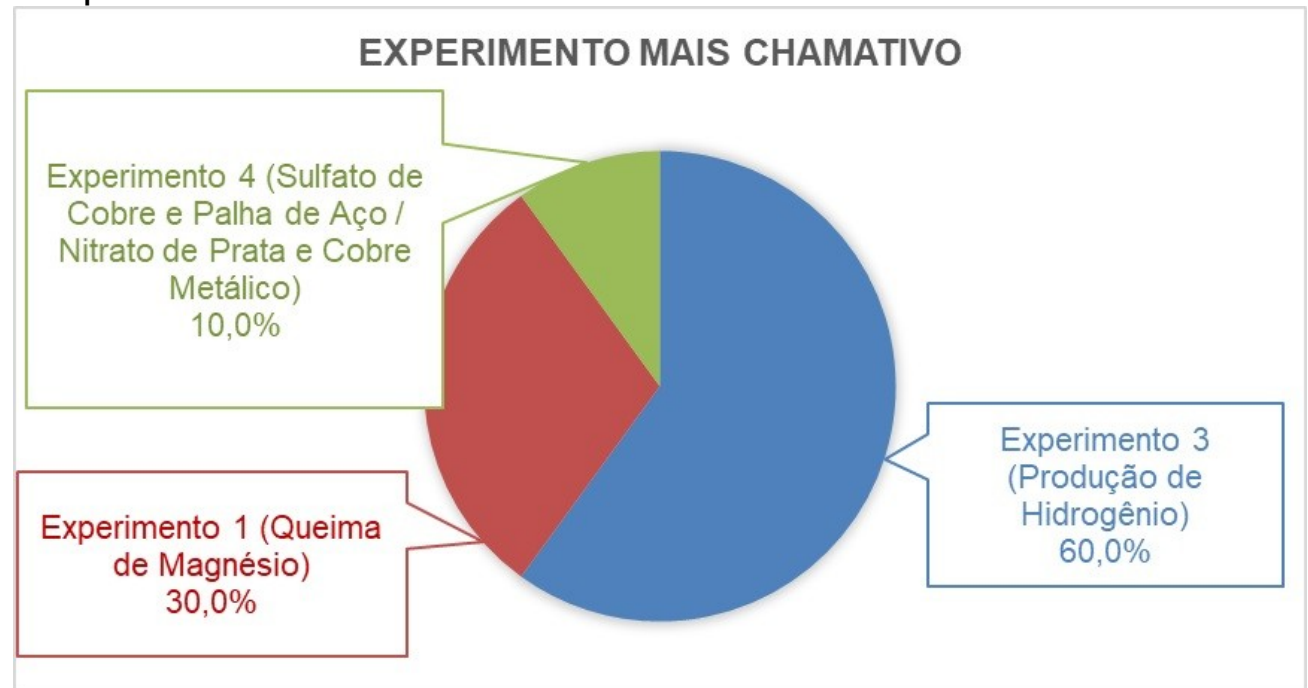

FIGURA 11: Experimento mais chamativo.

Fonte: Autores.

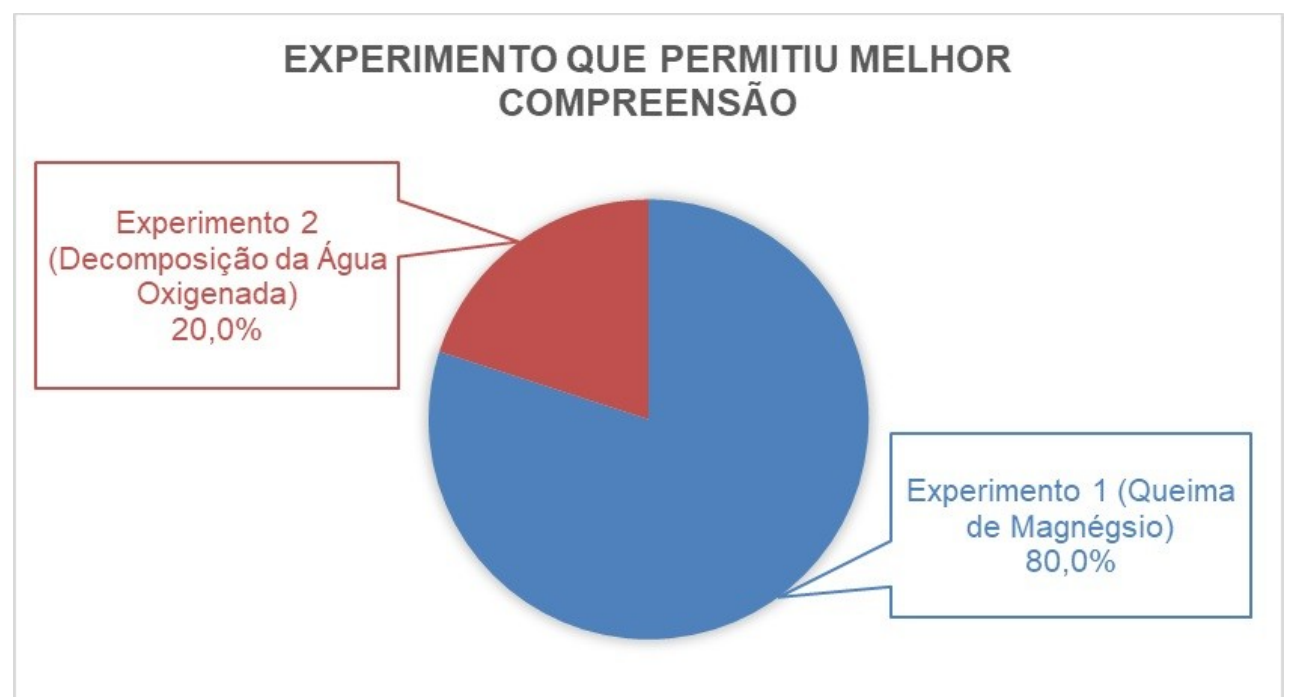

FIGURA 12: Experimento que permitiu melhor compreensão Fonte: Autores

\section{CONCLUSÃO}

A maioria dos alunos demonstrou interesse no assunto, assim como foram participativos e cooperativos nas atividades propostas, apenas um pequeno grupo não participou da aula e não quis realizar nenhum experimento na aula experimental. Verificou-se que muitos alunos que demonstraram animação por saber que haveria uma aula experimental, no momento de realizarem a experimentação, apresentavam medo, nervosismo ou preferiam permitir outra pessoa a realizar o experimento, mesmo ao serem comunicados que não havia nenhum risco à saúde. 
O experimento 5, referente a lei de proporção constante, mostrou-se complexo para os alunos, tanto para estes realizarem o procedimento, quanto para compreenderem o experimento. Sendo esta, uma possível razão dos alunos desenharem a tabela, mas não adicionarem a proporção de $\mathrm{Pb}\left(\mathrm{NO}_{3}\right)_{2}$ que reage com $\mathrm{KI}$.

Dos cinco relatórios entregues, dois eram idênticos, sendo diferenciados apenas por um estar digitado e o outro manuscrito. Devido a professora repassar que usualmente pede para os alunos realizarem relatórios de aulas experimentais, não foi dado um modelo ou padrão de relatório para que os alunos pudessem seguir. No roteiro de práticas experimentais há apenas o material e o procedimento para a realização do experimento, sem haver perguntas norteadoras, as quais teriam a função de direcionar os alunos quando estes realizassem o relatório.

A partir da análise dos dados coletados, alcançou-se o objetivo proposto pelo trabalho, no entanto, esperava-se maior rendimento dos alunos. A queda no rendimento esperado, pode estar relacionado à complexidade de alguns experimentos, o não uso de instrumento de pesquisa individual, o roteiro experimental não conter perguntas direcionando o aluno para a realização dos roteiros e não ser dado um modelo ou padrão de roteiro os alunos.

Desta forma, a proposta metodológica, apesar de contar com situações que possivelmente proporcionaram um menor rendimento de aprendizado dos alunos, é válida para o ensino de reações químicas para turmas da $1^{\circ}$ Série do Ensino Médio, pois a experimentação e a contextualização do conteúdo, além de tornar as aulas mais dinâmicas e interativas, faz com que o aluno crie associações com o seu cotidiano e consiga fixar o conteúdo de reações químicas inorgânicas.

\section{REFERÊNCIAS}

ATKINS, P. W.; JONES, L. Princípios de química: questionando a vida moderna e o meio ambiente. 5. ed. Porto Alegre/RS: Bookman, 2012.

BARRETO, B. S. J.; BATISTA, C. H.; CRUZ, M. C. P. Células Eletroquímicas, Cotidiano e Concepções dos Educandos. Química Nova na Escola, São Paulo/SP, v. 39, n. 1, p. 52-58, 2017. Disponível em: <http://dx.doi.org/10.21577/01048899.20160060>. Doi: 10.21577/0104-8899.20160060.

BICHO, V. A.; QUEIROZ, L. C. S.; RAMOS, G. C. A experimentação na educação de jovens e adultos: uma prática significativa no processo de ensino aprendizagem. Scientia Plena, São Paulo/SP, v. 12, n. 6, p. 1-8, 2016. Disponível em: <https://dx.doi.org/10.14808/sci.plena.2016.069923>.

Doi: 10.14808/sci.plena.2016.069923.

BRASIL. Ministério da Educação. Secretaria de Educação Média e Tecnológica. Parâmetros Curriculares Nacionais (Ensino Médio) (Parte III - Ciências da Natureza, Matemática e suas Tecnologias). Brasília (DF): MEC, p. 12-32, 1999. Disponível em: <http://portal.mec.gov.br/seb/arquivos/pdf/ciencian.pdf>.

FIGUEIREDO, A. M. T. A.; SAlES, F. R. P.; SILVA, C. M. Q.; SOUZA, N. S. Aplicação da Tabela Periódica em uma Turma Profissionalizante do Programa de Educação de Jovens e Adultos. Revista Principia - Divulgação Científica e Tecnológica do IFPB, João Pessoa/PB, n. 30, p. 31-38, 2016. Disponível em: 

03062015v1n30p31-38.

FUNDAÇÃO CECIERJ. Ciências da Natureza e suas Tecnologias: Química Fascículo 6, Unidade 14 e 15. Rio de Janeiro: CEJA, 2016. Disponível em: $<$ http://cejarj.cecierj.edu.br/material_impresso/quimica/ceja_quimica_unidade_15.pdf

KOGLER, J. T. S.; FRISON, M. D.; BEBER, L. C. C. A Experimentação Na Formação De Professores De Ciências: Memórias, Compreensões E Implicacões No Ensino. Revista da SBEnBio, Niterói/RJ, n. 7, p. 4133-4144, 2014. Disponível em: $<$ http://www.sbenbio.org.br/wordpress/wp-content/uploads/2014/11/R0880-1.pdf>.

I

LIMA, J. O. G.; BARBOSA, L. K. A. O ensino de química na concepção dos alunos do ensino fundamental: algumas reflexões. Exatas Online, Vitória da Conquista/BA v. $6, \quad$ n.1, p. 33-48, 2015. Disponível em: <http://www2.uesb.br/exatasonline/images/V6N1pag33-48.pdf>.

MARTINS, M. C. Turmas Heterogéneas No Ensino Superior: Um Desafio Para O Professor E Para O Aluno. European Scientific Journal, Lisboa-Portugal, v. 1, p. 242-249, $2014 . \quad$ Disponível em: <https://eujournal.org/index.php/esj/article/viewFile/4095/3929>.

MARTINS, R. A.; MARTINS, L. A. P. Lavoisier e a Conservação da Massa. Química Nova, São Paulo/SP, v. 16, n. 3, p. 245-256, 1993. Disponível em: $<$ http://quimicanova.sbq.org.br/imagebank/pdf/Vol16No3_245_v16_n3_ $\% 2814 \% 29$.pdf $>$.

MONTEIRO, T. H.; VANNUCCHI, H. Funções Plenamente Reconhecidas de Nutrientes: Magnésio. 1 ed. V. 16. São Paulo/SP: ILSI Brasil. 2010. Disponível em: <http://ilsi.org/brasil/wp-content/uploads/sites/9/2016/05/16-Magne\%CC\%81sio.pdf>.

MORTIMER, E. F.; MIRANDA, L. C. Transformações: concepções dos estudantes sobre reações químicas. Química Nova na Escola, São Paulo/SP, v.2, p. 23-26, 1995. Disponível em: <http://qnesc.sbq.org.br/online/qnesc02/aluno.pdf>.

NOVAES, F. J. M.; AGUIAR, D. L. M.; BARRETO, M. B.; AFONSO, J. C. Atividades Experimentais Simples para o Entendimento de Conceitos de Cinética Enzimática: Solanum tuberosum - Uma Alternativa Versátil. Química Nova Na Escola, São Paulo/SP, v. $35, \quad$ n. 1 , p. 27-33, 2013. Disponível em: <http://qnesc.sbq.org.br/online/qnesc35_1/05-RSA-104-11.pdf>.

SANTOS, D. O.; SILVA, G. S. Produção de hidrogênio a partir de materiais alternativos por alunos do Ensino Médio. Scientia Plena, São Paulo/SP, v. 11, n. 06, p. 1-8, 2015. Disponível em: <https://www.scientiaplena.org.br/sp/article/view/2520/1226>.

SILVA, A. M. Proposta para Tornar o Ensino de Química Mais Atraente. Revista de Química Industrial, Rio de Janeiro, v. 79, n. 735, p 7-12, 2011. Disponível em: <http://www.abq.org.br/rqi/2011/731/RQI-731-pagina7-Proposta-para-Tornar-oEnsino-de-Quimica-mais-Atraente.pdf>. 
SILVA, C. S.; CLEMENTE, A. D.; PIRES, D. A. T. Uso da Experimentação no Ensino de Química Como Metodologia Facilitadora do Processo de Ensinar e Aprender. Revista CTS IFG Luziânia, Luziânia/GO, V. 1, n. 1, p.1-18, 2015. Disponível em: <http://cts.luziania.ifg.edu.br/index.php/CTS1/article/view/31/pdf_3>.

SILVA JÚNIOR, E. A.; PARREIRA, G. G. Reflexões sobre a importância da experimentação no ensino da Química no ensino médio. Revista Tecnia, Goiânia/GO, v. 1, n. 1, p. 67-81, 2016. Disponível em: $<$ http://revistas.ifg.edu.br/tecnia/article/view/32/9>.

1

SCHWAHN, M. C. A.; OAIGEN, E. R. O uso do laboratório de ensino de Química como ferramenta: investigando as concepções de licenciandos em Química sobre o Predizer, Observar, Explicar (POE). Acta Scientiae, Canoas/RS, v. 10, n. 2, p. 151169 2008.

Disponível

em:

<http://www.periodicos.ulbra.br/index.php/acta/article/viewFile/73/63>.

TAHA, M. S.; LOPES, C. S. C.; SOARES, E. L.; FOLMER, V. Experimentação Como Ferramenta Pedagógica Para $\mathrm{O}$ Ensino de Ciências. Experiências em Ensino de Ciências, Uruguaiana/RS, v. 11, n. 1, p. 138-154, 2016. Disponível em: <http://if.ufmt.br/eenci/artigos/Artigo_ID305/v11_n1_a2016.pdf>.

TOKARNIA, M. Simulado do Enem: química e física são as áreas de maior dificuldade. Maio, 2016.2 Disponível em: <http://agenciabrasil.ebc.com.br/educacao/noticia/2016-05/simulado-do-enemquimica-e-fisica-sao-areas-de-maior-dificuldade>. 